\title{
A Lógica da Dialogicidade Narrativa no Repertório de Posições Pessoais ${ }^{1}$
}

\author{
Mariane Lima DeSouza ${ }^{2}$ \\ Universidade Federal do Espírito Santo \\ Manoela Z. Oliveira \\ Amanda DaSilveira \\ William B. Gomes \\ Universidade Federal do Rio Grande do Sul
}

\begin{abstract}
RESUMO - O objetivo deste estudo foi analisar as relações lógicas que fundamentam a abordagem dialógica do self e sua contraparte instrumental, o Repertório de Posições Pessoais (RPP). A análise partiu da evidência fornecida pela aplicação do RPP a 17 participantes com idade entre 19 e 34 anos ( 11 mulheres). Os resultados sugeriram dois contextos para o fenômeno da dialogicidade: a possibilidade de uma pessoa perceber-se como uma multiplicidade de características, e de construir narrativas sobre si a partir de diferentes pontos de vista. Esses resultados indicaram que o RPP é capaz de demonstrar a estrutura espacial da dialogicidade, mas não a dialogicidade em ação, que se revela um resultado da natureza narrativa do self. Para concluir, são discutidas limitações e possibilidades do RPP.
\end{abstract}

Palavras-chave: repertório de posições pessoais, self dialógico, narratividade, reflexividade

\section{The Logic of Narrative Dialogicality in the Personal Position Repertoire}

\begin{abstract}
The aim of this study was to analyze the logical relations behind the concept of dialogical self and its instrumental counterpart - the Personal Position Repertoire (PPR). This analysis relied on empirical evidence provided by the application of the PPR to 17 participants between 19 and 34 years old (11 women). Results suggested two different contexts for the phenomenon of dialogicality: the possibility for a person to perceive her or himself as a multiplicity of characters, and to construct narratives about her or himself from different points-of-view. These results indicate that the PPR is able to demonstrate the basic spatial structure of the dialogicality but not the dialogicality in action, that is an outcome of the self's narrative nature. To conclude, some limitations and possibilities for the PPR are discussed.
\end{abstract}

Key words: personal position repertoire, dialogical self, narrativity, reflexivity

O conceito de self $f^{3}$ dialógico é baseado na concepção de que o self e o diálogo partem de uma mesma estrutura básica (Hermans \& Kempen, 1993). Essa estrutura é construída por duas características motivacionais: dominância e troca intersubjetiva. Enquanto a dominância no comportamento de tomar a vez em um diálogo está relacionada à diferenciação e à autonomia do self, a troca intersubjetiva que se estabelece no diálogo corresponde à abertura e a participação no self (Hermans \& Kempen, 1993). O diálogo fornece a base para uma concepção descentralizada do self que é apresentada como uma alternativa às concepções cartesianas e individualistas. Na perspectiva dialógica, o self é definido como uma multiplicidade dinâmica de posições do eu relativamente autônomas, dotadas imaginariamente de uma voz a partir da qual relações dialógicas podem ser estabelecidas (Hermans, Kempen, \& Van Loon, 1992).

1 Apoio: CAPES e CNPq. Os autores agradecem a Glenda Almeida Pratti pelo trabalho de revisão dos originais.

2 Endereço para correspondência: Centro de Ciências Humanas e Naturais/DEPSD - UFES, Av. Fernando Ferrari, 512, Bairro Goiabeiras, Vitória, ES. CEP 29075-910.E-mail: limadesouza@gmail.com

3 Os autores seguem a mesma orientação de diversas publicações em língua portuguesa no Brasil, que adotam o termo self sem o uso do itálico (conferir Damásio, 1999/2000; Harré \& Gillett, 1999; Taylor, 1997 e Wiley, 1996)
O debate teórico em torno do modelo dialógico de self tem avançado consideravelmente na última década, recebendo contribuições e viabilizando aplicações empíricas em diversas áreas como a Psicologia do Desenvolvimento, a Psicologia Social, a Psiquiatria, a Neurobiologia e a Semiótica (ver Bertau \& Gonçalves, 2007). Por outro lado, as propostas metodológicas de investigação e avaliação do self dialógico não tem seguido no mesmo ritmo. Dessa forma, este artigo propõe-se a fazer uma análise crítica das possibilidades e das limitações metodológicas da investigação do self dialógico, a partir do exame de uma proposta específica de avaliação do fenômeno da dialogicidade, o Repertório de Posições Pessoais - RPP (Hermans, 2001). Busca-se compreender como o RPP de fato elicia e obtém acesso ao fenômeno da dialogicidade; se é um instrumento capaz de acessar a multiplicidade do self; e, de forma mais geral, qual é a natureza fenomenológica das posições do eu.

A resposta a esses questionamentos passa por um exame das relações lógicas subjacentes ao self, às posições, e à dialogicidade. Isto é, o desenvolvimento de um instrumento implica um raciocínio epistemológico complexo, no qual uma premissa afirma uma pressuposição epistemológica (o self dialógico como uma regra teórica) que é o contexto para uma questão epistemológica (como eu sei que o self é dialógico?). Tal artifício científico básico permite a invenção 
de um caso (o Repertório de Posições Pessoais) no qual a comparação interna de dois ou mais fenômenos (resultados) estabelece o mesmo contexto (o self dialógico como uma regra empírica) (conferir Lanigan, 1992). O desenvolvimento de um instrumento é, portanto, a execução de um raciocínio indutivo. No caso do Repertório de Posições Pessoais, um dos principais objetivos seria criar as condições apropriadas para o fenômeno da dialogicidade se manifestar. Primeiramente, é preciso eliciar o fenômeno, a fim de examinar como ele se manifesta.

Para tanto, inicialmente apresenta-se uma breve descrição do RPP e de outras propostas metodológicas de investigação do self dialógico, seguida de uma explanação dos aspectos mais importantes da abordagem dialógica do self. Em um segundo momento, são descritos os resultados de um estudo empírico no qual o instrumento foi aplicado a 17 participantes adultos jovens e adultos, para delimitar o foco problemático que norteia, logo em seguida, a discussão sobre a relação entre a dialogicidade e as possibilidades de avaliação desse fenômeno psicológico da consciência a partir do Repertório de Posições Pessoais.

\section{O Repertório de Posições Pessoais e as propostas metodológicas de investigação do self dialógico}

O Repertório de Posições Pessoais (Personal Position Repertoire) é uma proposta metodológica de acesso às relações dialógicas que se desenvolvem entre as diferentes posições do self, desenvolvida por Hermans (2001). Como um dispositivo de intervenção, o instrumento tem o objetivo de estimular no indivíduo a criação de narrativas alternativas, isto é, de uma nova percepção de si ou dos problemas que esteja enfrentando (Hermans, 2001). Através do RPP, é possível mapear e organizar o repertório de posições (positions) de uma pessoa (distinguidas entre internas - por exemplo, "eu como idealista" - e externas - por exemplo, "minha mãe"); com ênfase nos significados pessoais que estão associados com cada posição.

A aplicação do RPP na prática clínica psicoterápica já demonstrou sua adequação para mapear esse complexo repertório (Hermans, 2001; Santos, 2007). Esse é um ponto forte do instrumento, que resulta no desenvolvimento de uma gama de posições narrativas potenciais capazes de promover processos dialógicos, encorajando a pessoa a contar a sua história a partir de uma posição diferente (Gonçalves \& Salgado, 2001). Por outro lado, os diálogos que possivelmente estejam ocorrendo no exato momento em que o participante ou cliente está preenchendo o seu repertório não podem ser avaliados. Conforme Gonçalves e Salgado (2001), essa falha do RPP pode ser uma consequência do pressuposto implícito de que é possível para uma pessoa adotar uma metaposição que avalia todas as outras, isto é, uma espécie de posição neutra a partir da qual ela avalia a relação entre as outras posições. Já em outro estudo (Santos, 2007), que registrou a fala em voz alta dos participantes enquanto respondiam ao RPP, ficou evidente a dimensão temporal do self: a alternância entre diferentes pontos de vista parece sugerir que a organização descentralizada do self tem um caráter transitório.
O modelo do repertório de posições pessoais também já foi aplicado fora do contexto clínico, para investigar a estrutura da comunicação entre adolescentes através de SMS (short message system) como exemplifica o estudo de Cortini, Mininni e Manuti (2004). O estudo analisou um corpus de 3.890 mensagens do tipo SMS e concluiu que as novas mídias parecem de fato enfatizar o desenvolvimento das posições do self.

Inspirado nos pressupostos do Repertório de Posições Pessoais, o Personality Web (Raggatt, 2000), desenvolvido simultaneamente, combina uma estratégia qualitativa a uma quantitativa para eliciar e analisar conteúdos significativos (attachments) relacionados a pessoas, objetos, eventos de vida e percepções corporais. Já a Entrevista de Posições de Identidade (Identity Positions Interview) é um método elaborado para eliciar processos dialógicos durante a discussão de um problema pessoal (ver Cunha, 2007). Seguindo técnicas de psicoterapia, a entrevista permite ocorrência de diálogos reais (participante-pesquisador) e imaginários (participante-outro; participante no presente-participante no futuro). Cunha (2007) utilizou essa metodologia para investigar como ocorre a construção da organização do self através da multiplicidade, propondo uma análise microgenética da auto-organização no self dialógico. Mais tarde, Salgado (2008) refinou essa metodologia, renomeando o método como microanálise de posicionamento (Positioning Microanalysis). Tal procedimento alinha-se à proposta metodológica de Leiman (2002), cujo foco é a sequência dialógica, isto é, o processo semiótico através do qual se evidenciam as trocas de posições do self.

Com foco nos processos de construção de identidade, Duarte e Gonçalves (2007) desenvolveram uma metodologia que confronta o participante com a dualidade do self dialógico, denominada Tarefa de Articulação Dialógica (Dialogical Articulation Task-DAT). O estudo foi realizado com mulheres em um contexto de transição para a maternidade e concluiu que os modos através dos quais as mulheres negociam sua identidade maternal envolvem ambivalência e tensão entre os diferentes significados construídos.

Essas propostas metodológicas têm enfatizado um ou outro aspecto do modelo dialógico de self, com especial ênfase nas relações entre as posições. Contudo, ainda são necessários estudos no sentido de avançar sua contraparte metodológica.

\section{O modelo dialógico de self}

A noção de diálogo na teoria do self dialógico é um esforço para traduzir a distinção de James entre o eu e o mim "dentro da estrutura narrativa e dentro da estrutura conceitual do romance polifônico, em particular" (Hermans \& Kempen, 1993, p. 44). Os autores apontam uma similaridade entre o movimento na literatura representado pelo romance polifônico de Bakhtin e a abordagem narrativa na psicologia. A abordagem narrativa da realidade enfatiza o papel da imaginação na experiência humana consciente. De acordo com Hermans e Kempen (1993), evidências da penetração de narrativas na vida cotidiana são sugeridas por estudos que demonstram a estrutura narrativa da percepção (Michotte, 
1946/1963), emoção (Sarbin, 1989) e ação (Sarbin, 1990). As narrativas são definidas como uma conexão especial entre os vários eventos definida pela coerência, ao invés da ordem cronológica, que fornece a base para o desenvolvimento de estruturas significativas. Dessa forma, a abordagem narrativa com o seu foco no significado e na produção de significado oferece acesso direto ao self como um fenômeno dialógico (Hermans \& Kempen, 1993). A tradução clássica da distinção de James entre Eu-Mim dentro de uma abordagem narrativa é baseada nos trabalhos de Mancuso e Sarbin (1983) e Sarbin (1986). Nessa perspectiva, o pronome eu diz respeito ao autor, e o pronome mim diz respeito ao ator ou figura narrativa. Essa distinção define o self como o autor de uma narrativa na qual ele mesmo ou ela mesma é descrito/a como um ator/ atriz. De fato, o self é visto como a narrativa: "a noção de 'história' ou 'narrativa' supõe a existência de uma pessoa que fala e uma pessoa real ou imaginária que ouve [grifos do autor]" (Hermans \& Kempen, 1993, p. 45).

A distinção narrativa entre autor e ator ou personagem e o foco no fenômeno dialógico encontra uma importante correspondência no trabalho do estudioso literário russo Mikhail Bakhtin (1929/1973). Inspirado pelo conceito de Bakhtin de romance polifônico e relações dialógicas, a abordagem do self dialógico resulta em uma visão de narrativa que enfatiza a espacialização do tempo. A noção de narrativa como uma estrutura temporal com um princípio, uma ação e um final é ampliada para abranger desenvolvimentos ao longo do tempo justapostos em estruturas espaciais. As justaposições (espacialização das diferenças temporais) permitem, assim, o surgimento de novos relacionamentos entre as posições dialógicas. Como resultado, a narrativa é definida como uma estrutura espaço-temporal, onde o tempo e espaço assumem igual importância.

As noções de narrativa e diálogo imaginários estão integradas em uma concepção do self como uma multiplicidade de posições do eu. Isto é, ao invés de um narrador onisciente, o self é definido como o autor que participa do romance e fala através da voz de um ou mais personagens. As possibilidades dessa transposição das ideias de Bakhtin para o contexto da problemática psicológica foram especialmente discutidos nos trabalhos de dois psicólogos russos, Vasil'eva (1988) e Florenskaya (1989). Segundo Vasil'eva (1988), apesar de não ter um estilo exatamente científico, mas sim literário, a teoria de Bakhtin pode revelar conteúdos psicológicos. A essência da comunicação humana é revelada dentro do sistema de conceitos que descrevem o processo comunicativo e seus principais componentes. No mesmo sentido, o trabalho de Bakhtin na análise literária é elaborado à luz da problemática psicológica da fala interna, quando enfatiza "a peculiaridade e a igualdade de status de duas vozes em um campo comunicativo e no domínio da consciência individual" (Florenskaya, 1989, p. 35).

$\mathrm{Na}$ abordagem dialógica do self, a metáfora do romance polifônico tem função ontológica: situa a dialogicidade em uma dimensão espacial, uma vez que enfatiza a simultaneidade, a justaposição e a descontinuidade das vozes (DeSouza \& Gomes, 2009). Nesse sentido, ao invés de coerência no self, o diálogo focaliza a separação intrínseca das contrastantes posições do eu situadas dentro do tempo espacializado ou do espaço temporalizado. Hermans et al. (1992) sublinham a natureza espacial do self ao optarem pelos termos "posição" e "posicionamentos" (position and positioning), por serem mais dinâmicos e flexíveis, em substituição ao termo "papel" (role). O principal objetivo é distinguir posições, especialmente as internas, de traços. A diferença evidente é que as teorias de traços assumem a permanência e a estabilidade, enquanto as posições são investigadas como qualidades específicas de uma determinada situação, podendo modificar-se caso a situação se altere. A diferença mais essencial é que as posições são autorreflexivas e os traços não são. Consequentemente, traços não podem entrar em conflito ou tampouco integrar-se uns aos outros como fazem as posições. Hermans (2001, p. 332) explica essas diferenças nos seguintes termos:

Enquanto o termo traço assume uma reificação da pessoa em termos de um perfil de personalidade, as posições são entendidas como posições do eu e, como tal, são autorreflexivas e autoavaliativas. Não apenas as posições internas, mas também as posições externas funcionam como posições do eu: posso ter a perspectiva de, digamos, meu pai e imaginar como ele vê a si mesmo, suas relações com meus irmãos e comigo.

\section{A ênfase na espacialidade do self}

A despeito da flexibilidade dialógica das posições, a ênfase no espaço ao invés de no tempo implica a pressuposição de que um indivíduo pode adotar uma postura narrativa ou autoral, de alguma forma acima dos personagens que constituem o self dialógico e polifônico (Barresi, 2002). Essa proposição parece levar à perigosa conclusão de que o self pode mover-se para fora da consciência daquele que fala. Na visão de Barresi (2002, p. 248), a concepção de que um indivíduo pode falar com quase a mesma facilidade tanto da perspectiva de sua voz dominante, quanto da perspectiva da voz de alteregos implica uma impossibilidade epistemológica: "sugerir que isso possa acontecer é assumir que a consciência pode encerrar a si mesma dentro de um modelo que ela cria de uma outra consciência”. O que Barresi (2002) define como uma impossibilidade epistemológica, Wiley (1994) chama de "ponto cego do self", isto é, a indisponibilidade cognitiva do eu para si mesmo. De fato, a noção de metaposição de Hermans (2001, p. 354) como um tipo especial de posição do eu que "contribui, mais que outras posições, para a integração e unidade do repertório" parece apagar a hipótese clássica do ponto cego da consciência. Mas, a favor da ideia de Hermans, Wiley (1994) explica que o self pode circundar seu próprio ponto cego. E, adotar um "meta" nível ou uma visão externa é uma maneira prática na qual o self pode observar a si mesmo, não de dentro, mas de fora, via uma posição de alteridade. Portanto, a metaposição na abordagem dialógica do self deve ser entendida não como um tipo especial de posição do eu, mas como um dispositivo reflexivo subjacente a todas as posições que o eu assume.

\section{Método}

O estudo seguiu uma abordagem qualitativa (Creswell, 2010), conforme os critérios da fenomenologia-semiótica 
(Gomes, 1998; Lanigan, 1992), e pode ser caracterizado como descritivo de acordo com seus objetivos e como ex-post facto de acordo com seus procedimentos técnicos (Gil, 2002).

\section{Participantes}

Participaram do estudo 17 indivíduos, com idade entre 19 e 34 anos (11 mulheres), de classe média baixa com diferentes níveis educacionais, do ensino médio ao superior.

\section{Instrumentos e procedimentos de coleta de dados}

Foram utilizados dois instrumentos para a coleta de dados: 1) Repertório de Posições Pessoais (Hermans, 2001) e 2) Protocolo de questão única (Como foi a experiência de responder ao RPP?).

O RPP é uma ferramenta de avaliação psicológica que une uma estratégia qualitativa a uma estratégia quantitativa. As duas estratégias compõem duas matrizes complementares, a Matriz de Posições Internas e Externas e a Matriz de Valorações e Afeto. As matrizes pressupõem a existência de uma relação hierárquica entre as posições, valorações e afetos (Hermans, 2001), em três níveis. O nível mais alto é onde o eu pode ser localizado, nas suas mais diferentes posições, a partir das quais conta uma história específica sobre o Mim que pertence àquela posição, expressando diferentes unidades de significado (nível médio), cada uma com suas conotações afetivas específicas (nível mais baixo).

A primeira parte do RPP é constituída por uma lista de 50 posições internas (por exemplo, "eu como mulher", "eu como profissional", "eu como alguém que busca liberdade", "eu como sexual", "eu como idealista", "minha consciência", "a criança em mim", "como eu sou comigo mesmo") e 41 posições externas (por exemplo, "meu marido/companheiro", "minha esposa/companheira", "minha mãe", "meu colega", "uma figura em meu sonho", "alguém que está morto", “um grupo ou sociedade ao qual eu pertenço", "minha casa") apresentadas ao participante com a solicitação de que escolha aquelas nas quais se reconhece e que desempenham algum papel em sua vida. O participante também pode adicionar posições, nomeando-as com seus próprios termos. Logo em seguida, o participante é solicitado a estimar a extensão na qual, em sua experiência, cada posição interna selecionada é proeminente (de forma positiva ou negativa) em relação a cada posição externa selecionada. Para essa estimativa, o participante deve utilizar uma escala do tipo Likert, que varia de 0 a 5 (na qual $0=$ nenhum, $1=$ muito pouco, $2=\mathrm{em}$ algum grau, 3 = bastante, $4=$ consideravelmente, $5=$ muito consideravelmente). O resultado final é uma matriz, na qual as posições internas são representadas nas linhas, as posições externas são representadas nas colunas e a intensidade da proeminência de uma posição sobre a outra é representado em cada célula gerada no cruzamento de ambas.

Na segunda parte, a Matriz de Valorações e Afeto, o participante fica livre para escolher duas posições, a partir das quais deverá montar uma narrativa, construída conforme um protocolo de questionamentos elaborados para eliciar valorações. Essa etapa funciona como uma entrevista semi- -estruturada, na qual o pesquisador utiliza as questões para guiar o participante na construção de uma autonarrativa em uma dimensão temporal que envolva passado, presente e futuro. $\mathrm{O}$ resultado é uma narrativa contendo as valorações relacionadas às duas posições selecionadas pelo participante. Finalmente, o participante é novamente solicitado a avaliar (usando a mesma escala descrita anteriormente) em que extensão os eventos e pessoas na sua vida afetaram a relação para cada valoração previamente eliciada. Essa etapa final fornece o perfil afetivo de cada valoração.

A listagem padronizada de posições internas e externas, bem como a listagem padronizada de afetos, e a entrevista semi-estruturada foram traduzidas para a língua portuguesa pelos autores e novamente traduzidas para o inglês por um pesquisador bilíngue. As inconsistências foram discutidas e resolvidas por todos os autores.

Todos os participantes assinaram um Termo de Consentimento Livre e Esclarecido e para todos os procedimentos da pesquisa foram observados os padrões éticos definidos pelos regulamentos nacionais e internacionais de pesquisa, tendo o protocolo aprovado pela Comissão de Ética em Pesquisa da instituição na qual os dados foram coletados. A aplicação da versão completa do RPP se deu em dois encontros em semanas diferentes. Na primeira semana, eles responderam à primeira parte, a Matriz de Posições Internas e Externas, e completaram o RPP na segunda semana, respondendo a entrevista semi-estruturada e completando a Matriz de Valorações e Afeto. Ao final, os participantes foram também solicitados a expressar suas impressões gerais sobre o instrumento, de forma escrita. O RPP é explicado para os participantes, utilizando como metáfora, a encenação de uma peça de teatro, conforme sugerido em Hermans (2001). Os participantes são convidados a imaginar um palco de teatro, no qual um número de personagens (posições internas) entram no palco pela esquerda, e um número de personagens (posições externas) entram no palco pela direita. Então, explica-se que o RPP foi elaborado para estudar como os dois grupos de personagens estão ligados uns aos outros, tanto intra quanto intergrupalmente.

\section{Procedimento de análise dos dados}

O levantamento do RPP seguiu as diretrizes de Hermans (2001). A análise dos dados obtidos através do protocolo de questão única, assim como a análise de todo o corpus de dados seguiu os três passos da fenomenologia-semiótica: descrição, redução e interpretação (Gomes, 1998; Lanigan, 1992). A descrição fenomenológica consiste em apresentar os dados coletados sem um pré-julgamento, apontando o contexto temático do fenômeno investigado. A redução fenomenológica procura trazer à tona características essenciais ao fenômeno estudado, recortando o foco problemático. A interpretação fenomenológica explicita uma lógica resultante da unificação entre a experiência consciente do fenômeno e a consciência dessa experiência, oferecendo uma compreensão do objeto estudado que o coloca em perspectiva, a partir da comparação e do contraste com outras compreensões (no caso, outros estudos empíricos e/ou teóricos já publicados na área). 


\section{Resultados}

\section{Descrição fenomenológica}

Os participantes selecionaram e compreenderam facilmente as posições. Oito posições internas foram adicionadas à listagem padronizada por diferentes participantes: "eu como criativo", "eu como amigo", "eu como cristão", "eu como ser humano", "eu como alguém que admira o passado", "eu como rancoroso", "eu como poeta", "eu como alguém que renuncia o presente". A posição interna "eu como compreensivo" foi a mais selecionada (apareceu no repertório de 16 participantes), seguida imediatamente pelas posições "eu como alguém que busca liberdade" e "como eu sou comigo mesmo" (apareceram no repertório de 15 participantes), e por "eu como filho/a dos meus pais", "eu como alguém que busca afeto", "eu como alguém que busca reconhecimento", "eu como sonhador", "a criança em mim", e "como eu me mostro em público" (apareceram no repertório de 14 participantes). As posições internas acrescentadas pelos participantes, exceto Eu como amigo, apareceram no RPP de apenas um participante. Os participantes também acrescentaram três posições externas à listagem padronizada: "meus amigos", "meus sobrinhos", e "minha tia". A posição externa "minha mãe" foi a mais selecionada (apareceu no repertório de 16 participantes), seguida imediatamente por "alguém que eu admiro" (apareceu no repertório de 15 participantes). A posição interna "meu subordinado" não foi selecionada por nenhum dos participantes. As posições "alguém que pratica esportes comigo", "meus sobrinhos" e "minha tia" (essas duas últimas acrescentadas pelos participantes) apareceram em apenas um repertório.

Os resultados da Matriz de Valorações e Afeto (segunda parte do RPP) serão exemplificados a partir da descrição qualitativa de três casos. O critério para seleção desses casos obedeceu às exigências qualitativas para apresentação de um caso: casos ilustrativos devem abranger a variação e constituir a estrutura essencial do fenômeno sob investigação (Lanigan, 1992). Esses participantes foram convidados a participar de uma pesquisa sobre autoconsciência, quando contataram o serviço psicológico gratuito oferecido em uma universidade pública do estado do Rio Grande do Sul para orientação profissional. Os nomes foram modificados para preservar o anonimato dos participantes. Os casos são descritos a seguir.

\section{Caso 1 - João, o jovem inquieto}

João é um adulto jovem (22 anos) de classe média, que vive em um bairro pobre e pretende ser um escritor. Ele tem escrito contos desde os 12 anos. João definiu a si mesmo como alguém que não consegue ficar parado. Seu plano é fazer o curso de letras, mas ele reprovou no exame de vestibular duas vezes. João buscou orientação profissional para "saber exatamente as futuras perspectivas do que ele quer fazer" (sic). Ele escolheu contar uma história a partir da posição interna "sonhador". A narrativa descreve o período de sua infância, quando sua mãe estava viva, como o mais significante para que ele se tornasse o que ele é hoje.
A mãe foi a pessoa mais importante durante esse período de sua vida. Hoje, a arte (romances, música e poesia) é a coisa mais importante para ele. Ele gostaria de ser independente para decidir o que fazer com o seu próprio dinheiro. Sobre o futuro do "sonhador", a narrativa descreve alguém que quer ajudar pessoas pobres, especialmente estimulando o desenvolvimento de novos talentos artísticos.

\section{Caso 2 - Clara, a única filha que não está na universidade}

Clara é uma jovem de 19 anos de idade, estudante de pré-vestibular. Ela é a mais nova de três irmãs e se define como a única que não está na universidade. Clara reprovou três vezes no exame de vestibular, cada um para uma área diferente. Agora ela está realmente certa sobre o que quer fazer e veio para o serviço de orientação profissional seguindo o conselho de sua mãe. Clara escolheu contar uma história a partir das posições "filha de meus pais" e "sonhadora". Como "filha de meus pais", a narrativa começou relembrando o quanto seus pais sempre satisfizeram todos os seus desejos e que sua mãe foi sempre muito próxima a ela. Hoje, ela sente seu lado artístico como a coisa mais importante da vida. A pessoa mais significativa é sua irmã. No futuro, Clara quer se tornar independente através de seu trabalho. Sobre a posição "sonhadora", Clara lembrou como queria ser uma desenhista na infância, mas todos sempre a avisavam para sonhar, mas com os pés no chão. Hoje, ela deseja que seus sonhos se tornem realidade. No futuro, Clara pretende viver sozinha, mas com a ajuda da mãe e se vê como uma professora.

\section{Case 3 - José, um adulto em busca de emprego}

José é um adulto de classe média ( 29 anos de idade) que mudou com a sua noiva para um outro estado à procura de trabalho. Ambos estão desempregados há quase um ano. José trabalhou em vários e diferentes empregos, mas não gostou de nenhum deles. Agora, ele diz sentir-se "perdido" (sic), mas ele provavelmente iria aceitar qualquer trabalho porque ele precisa de dinheiro. José escolheu contar sua narrativa a partir da posição externa "minha casa" e da posição interna "como eu me mostro em público". Sobre a posição "minha casa", José lembrou de um evento na infância quando sua mãe comprou uma casa e eles se mudaram. Hoje ele se sente muito triste porque ele não tem casa própria. A pessoa mais importante para ele é sua noiva. A narrativa de José finaliza com metas para o futuro imediato, como começar a trabalhar e a juntar dinheiro. A partir da posição "como eu me mostro em público", José narrou um incidente no seu último trabalho, quando ele discutiu com alguém e disse palavras imprudentes. Hoje ele sente vergonha e gostaria de mostrar às pessoas do que ele é capaz. A pessoa mais importante na sua vida presente é a sua família. No futuro, novamente um futuro imediato, por volta de um ano quando estiver com 30 anos, José quer se estabelecer profissionalmente.

A análise fenomenológica das respostas ao protocolo de questão única revelou três categorias: 1) autocompreensão; 2) crítica e 3) dúvida. A categoria "autocompreensão" abrange impressões positivas do RPP, relacionadas a uma 
sensação de satisfação e, especialmente, de crescimento pessoal. Isto é, o RPP foi caracterizado como um instrumento que viabiliza uma percepção mais ampla e complexa de si. A categoria "crítica" abrange impressões negativas do RPP, definido como um instrumento difícil de responder e distante da realidade. Tais impressões foram relacionadas principalmente à tarefa de estimar a intensidade e proeminência da relação entre as posições internas e externas, bem como à tarefa de se colocar na perspectiva de uma posição específica para elaborar uma pequena narrativa, e em seguida, trocar de posição, elaborando outra narrativa. A categoria "dúvida" abrange um questionamento quanto à adequação das respostas dadas ao RPP, relacionadas a uma possível incoerência de se selecionar como características próprias, posições opostas entre si.

\section{Discussão}

\section{Redução fenomenológica}

A percepção dos participantes apontou um foco problemático composto por dois pontos: a divisão das posições em tipos internos e externos e as divisões do self em múltiplas características. O primeiro ponto refere a dificuldade para compreender as posições externas como componentes do sistema do self:

No inicio, era difícil relacionar as duas listas de posições (...) Eu coloco junto o que eu sou com as pessoas ou [com] o que eu penso sobre elas? (P10).

O segundo ponto refere a dificuldade de perceber a multiplicidade do self como uma característica autônoma:

Eu não posso me ver em cada posição interna separadamente (P07).

Eu estou sendo coerente? (P09).

Nesse sentido, os resultados do RPP sugerem dois diferentes contextos para o fenômeno de dialogicidade do self, definidos pelas duas partes do instrumento, respectivamente, a matriz de posições internas e externas e a matriz de valorações e afetos. O primeiro contexto demonstrou a possibilidade para uma pessoa de perceber-se como uma multiplicidade de características divergentes e até opostas entre si. Embora experienciadas com certa estranheza e mesmo com uma atitude crítica, tais características foram percebidas e expressadas não apenas em termos de adjetivos mais conhecidos (compreensivo, desiludido, e sonhador), mas foram também percebidas em termos de expressões autodefinidoras mais complexas (eu como alguém que busca liberdade, como eu sou comigo mesmo, eu como filho/a dos meus pais, eu como alguém que busca afeto, eu como alguém que busca reconhecimento, a criança em mim, e como eu me mostro em público), como indicado pelas mais frequentes posições internas selecionadas no repertório dos participantes. A autopercepção dos participantes no domínio externo também expressa essa multiplicidade, ao colocar juntos os termos mãe, alguém que eu admiro, e casa, por exemplo (as posições externas mais selecionadas) no seu repertório.

\section{Interpretação fenomenológica}

Em um sentido estrito, portanto, os repertórios dos participantes podem ser tomados como uma expressão da dialogicidade do self: quando os participantes reconhecem e selecionam tantos e tão diferentes termos como significativos em suas vidas, eles estão dotando de voz aspectos diferentes de si mesmo. Essa evidência realiza o primeiro objetivo do Repertório de Posições Pessoais, que é a "polifonização do self", nos termos de Hermans (2001, p. 351): "A estratégia é primeiro decentralizar o self tanto quanto possível a fim de estabelecer ligações e conexões entre as posições para uma fase posterior do procedimento".

Por outro lado, os dois pontos revelados no processo de relacionar posições internas e externas - a dificuldade de compreender as posições externas como componentes do sistema do self e a dificuldade de perceber a multiplicidade do self enquanto personagens autônomos - parecem sugerir uma limitação do Repertório de Posições Pessoais em eliciar e avaliar o self dialógico, mais do que uma impossibilidade do participante em experienciar o fenômeno da multiplicidade. Uma explicação para essa limitação do instrumento pode ser o uso de vocabulário analítico e contraintuitivo que, se por um lado, auxilia na revelação de insights usualmente encobertos pela terminologia cotidiana (Bamberg \& Zielke, 2007), por outro, distancia a consciência da experiência. De fato, de uma perspectiva fenomenológica, interessa justamente o desvelamento do fenômeno, ou, nos termos de Husserl (1986), voltar-se para as coisas mesmas e transformar a experiência da consciência em consciência da experiência, mas sempre por meio da suspensão de tudo que é dado a priori, objetivando uma descrição radical da experiência vivida.

Essas dificuldades, contudo, mais que uma limitação, podem ser vistas como evidência da eficácia da divisão interno/ externo como um artefato para mapear a multiplicidade do self. A estranheza suscitada tanto pela divisão das posições em internas e externas quanto pela possibilidade de posições opostas e contraditórias estarem combinadas no próprio repertório, mapeado em um único momento, são o resultado do esforço constante da consciência para construir uma imagem de coesão e unidade de si própria que seja estável. Conforme Valsiner (2002), as relações dialógicas entre as posições do eu são mantidas e desenvolvidas no interior do self, concebido como um sistema. Uma vez que as relações dialógicas são dinâmicas, as partes do sistema podem reagrupar-se (Hermans, 2000). De qualquer forma, o foco teórico é orientado para a dinâmica dos relacionamentos, ao invés de ser orientado para os componentes do sistema (Valsiner, 2002, p. 251): "Dialogicidade é a propriedade geral do sistema que implica o estabelecimento de relações entre suas partes como sendo definitivas para o mesmo: sistema $\mathrm{W}=(\mathrm{A}<>\mathrm{B})$, onde $<$ indica um relacionamento dialógico". A manutenção da estabilidade dinâmica é uma necessidade crucial para o self dialógico, na medida em que essa estabilidade é um estado temporário sempre substituído pela instabilidade. Então, o 
self dialógico pode ser caracterizado como uma unidade de flexibilidade e inflexibilidade. Em outras palavras, uma flexibilidade de funções é determinada pela emergência de uma organização hierarquica do self dialógico como uma síntese (Valsiner, 2002).

A principal qualidade distintiva das posições é sua capacidade de estabelecer conflito ou integrarem-se umas com as outras e interligar os domínios interno e externo. Por exemplo, na expressão do participante "estou sendo coerente?", a palavra "coerente" expressa claramente a percepção do participante sobre o caráter conflitivo das posições. Da mesma forma, a pergunta do participante "Eu coloco junto o que eu sou com as pessoas ou o que eu penso sobre elas?" indica o entrecruzamento entre os domínios interno e externo como uma característica inerente às posições.

O segundo contexto demonstrou a possibilidade para uma pessoa de construir narrativas sobre si mesma, a partir de diferentes pontos de vista. Essas diferentes perspectivas envolvem não apenas personagens internos como, por exemplo, "filho dos meus pais" e "sonhador" (caso de Clara), "como eu me mostro em público" (caso de José), mas também posições externas não apenas relacionadas a pessoas, como "minha casa" (caso de José). A Matriz de Valorações e Afetos de João ilustrou um importante contraponto: ele não quis escolher mais de uma posição (além de "sonhador") porque, nas suas palavras, de outra posição ele iria contar uma história muito semelhante. Isto é, os participantes puderam contar uma pequena narrativa sobre a posição mais importante na sua percepção para aquele momento da vida deles; contudo, a possibilidade de transitar entre diferentes posições e dar voz a cada uma delas, de forma autônoma, nem sempre é uma experiência simples, fácil ou mesmo desejável de consciência. O movimento dinâmico entre diferentes posições do self pode não ser fenomenologicamente experienciado, como o caso de José ilustra. Ele se posicionou em uma estática e confortável posição de onde montou uma narrativa sobre si como um "sonhador".

Os dois contextos revelados pela evidência empírica assinalam as limitações e possibilidades do RPP como um artefato para acessar a dialogicidade do self. Embora de forma restrita, é possível verificar a capacidade do instrumento de avaliar a multiplicidade dinâmica de posições do eu imaginativamente dotadas de vozes. De fato, esse fenômeno foi observado qualitativamente nas respostas ao RPP. Entretanto, o instrumento de Hermans foi capaz de demonstrar a estrutura básica da dialogicidade, mas não a dialogicidade como processo. Por analogia, o RPP pode ser entendido mais com uma foto que representa um momento estático, do que como um filme, que apresenta uma sequência temporal de eventos. Nesse sentido, o instrumento parece refletir, justamente, uma lacuna do próprio modelo teórico do self dialógico. Como sugere Raggatt (2010), a teoria do self dialógico fornece um interessante panorama do self extendido no tempo, no espaço e na cultura, mas, falha em esclarecer mais detalhadamente o funcionamento psicológico da dialogicidade. Contudo, estudos na área da psicologia do desenvolvimento (Barresi, 2007; Bertau, 2007; Fogel, Koyer, Bellagamba, \& Bell, 2002; Lyra, 2005) bem como na área da neurobiologia (Lewis, 2002) vêm preenchendo essa lacuna no sentido de fornecer uma compreensão do self dialógico como uma condição ontológica inerente ao fenômeno da experiência consciente do self. De fato, a relação entre self, definido como um processo reflexivo consciente, e diálogo enquanto fala interna já foi discutida em DeSouza, DaSilveira e Gomes (2008). Evidências fornecidas por estudos sobre os correlatos neurobiológicos da autoconsciência sugerem que a fala interna está profundamente ligada à autoconsciência e à auto-reflexão (Morin, 1993, 2001, 2002, 2003). Para Morin (2003), a fala interna é o que nos torna conscientes de nossa existência. Ainda assim, especificamente com relação ao self dialógico, o modelo realístico neural baseado em uma neurobiologia das emoções proposto por Lewis (2002) sugere que, em termos de funcionamento cerebral, as evidências indicam posições do eu semi-autônomas, mas não coexistentes.

Por outro lado, a concepção de self dialógico inspirada pela formulação de James eu-mim, na qual o pronome eu está para o autor e o pronome mim está para o ator ou figura narrativa implica uma formulação de dialogicidade que iguala as narrativas construídas pelas diferentes posições à autonarrativa produzida pelo eu. Mas, se a dialogicidade é constituída por diferentes e variadas posições-narrativas não se pode indicar quais narrativas são produzidas pelos mim-atores e quais são produzidas pelo eu-autor e, tampouco, qual das narrativas é obtida pelo RPP.

O foco do self dialógico é a dinâmica das relações que aparecem nas narrativas do self. Por sua vez, a autonarrativa é uma conexão entre muitos eventos que segue a lógica da coerência. Outro nome para isso é significado, que é o mesmo que experiência consciente humana. De fato, uma narrativa é uma condição empírica, que fornece acesso ao self como um fenômeno dialógico. A narrativa é uma expressão da experiência consciente que, enquanto tal, é um processo reflexivo. O processo reflexivo é uma conversação contínua entre a experiência consciente e a experiência da consciência. Em outras palavras, o diálogo entre as diferentes posições do eu é uma consequência da comunicação. É essa condição que permite e justifica o uso da metáfora do self dialógico. Segundo Wiley (1994), a maior parte da comunicação ocorre entre remetente e destinatário, mas uma importante parte é interna e reflexiva. Isto é, a experiência consciente de si é um ato comunicativo que ocorre entre um remetente e ele mesmo. Essa reflexividade é a condição fundamental para a comunicação e, então, para a experiência consciente como uma experiência da consciência, isto é, o senso de self. O self é uma capacidade universal e genérica de produzir a si mesmo como significado. Essa definição de self como processo reflexivo que funciona como um ato comunicativo propõe, justamente, uma alternativa à concepção de um self restritivamente mental que se apoia na metáfora da internalização e que tende a incutir a noção de dialogicidade e posicionamento no self (Bamberg \& Zielke, 2007). Além disso, busca superar a questão sobre se a definição de self deve ou não ser restrita a processos reflexivos conscientes, colocada por Santos e Gomes (2010), a propósito do debate entre Lysaker (2006) e Wiley (2006). Do mesmo modo que os primeiros autores, entendemos que o self pode englobar aspectos conscientes e inconscientes, reflexivos e pré-reflexivos (Santos \& Gomes, 2010).

Dessa forma, as posições do eu podem ser compreendidas como identidades diferentes, isso é, como designações 
posicionais internalizadas que constituem partes do self (Rosenberg \& Turner, 1981). Nesse sentido, como lembra Wiley (1994), uma diferenciação entre identidades particulares e self genérico tem que ser colocada: identidades não são análogas ao self. As identidades emergem com o self no meio social, mas elas podem ser aumentadas, modificadas, diminuídas ou mesmo desaparecer. Essa diferenciação é fundamental para qualquer alternativa à concepção cartesiana de self.

\section{Conclusão}

A invenção de um caso é um artifício para analisar a correspondência entre o constructo e seu instrumento. A análise epistemológica no presente estudo partiu da invenção de um caso (a aplicação do Repertório de Posições Pessoais a 17 voluntários), no qual dois fenômenos (a composição de um repertório de posições pessoais e a construção de narrativas) foram internamente comparados e estabeleceram o mesmo contexto (a regra empírica que sugere o Repertório de Posições Pessoais como um artefato adequado para acessar o self dialógico, mas inadequado para acessar a dialogicidade do self em ação). Esse contexto, isto é, essa regra empírica permitiu definir os limites e possibilidades do RPP como instrumento de avaliação do self. A dialogicidade posicional circunscreveu o território do self como um espaço: o RPP mapeou uma estrutura de variadas posições do eu, mas foi menos apto a revelar a relação dialógica como processo, ou, em outros termos, não forneceu indícios da dominância ou da troca intersubjetiva entre as posições do eu. Portanto, a dialogicidade não pode ser identificada como um construto revelado diretamente pelo RPP de um indivíduo em um determinado momento. A dialogicidade como qualidade básica do processo reflexivo da consciência possivelmente deve se revelar na comparação entre dois ou mais repertórios de posições pessoais de um indivíduo em momentos diferentes de sua vida. A despeito da ênfase na espacialidade do self, a dialogicidade aparece mais como um resultado da natureza narrativa e temporalizada do self, pois são as narrativas que permitem um intercâmbio de posições do eu, fomentando a relação dialógica entre elas. E o próprio Repertório de Posições Pessoais de um indivíduo pode ser reorganizado a partir de modificações que o self realiza na narrativa que está continuamente elaborando.

\section{Referências}

Bakhtin, M. (1973). Problems of Dostoevsky's poetics (R. W. Rotsel, Trad.). Ann Arbor: Ardis (Originalmente publicado em 1929)

Bamberg, M., \& Zielke, B. (2007). From dialogical practices to polyphonic thought? Developmental inquiry and where to look for it. International Journal for Dialogical Science, 2, 223-242. Retrieved from http://ijds.lemoyne.edu/journal/2_1/ index.html

Barresi, J. (2002). From 'the Thought is the Thinker' to 'the Voice is the Speaker'. Theory \& Psychology, 12, 237-250.
Barresi, J. (2007). The origins of autism: a commentary on Muratori \& Maestro's “Autism as a downstream effect of primary difficulties in intersubjectivity interacting with abnormal development of brain connectivity. International Journal for Dialogical Science, 2, 119-124. Retrieved from http://ijds. lemoyne.edu/journal/2_1/index.html

Bertau, M. C. (2007). On the notion of voice: an exploration from a psycholinguistic perspective with developmental implications. International Journal for Dialogical Science, 2, 133-161. Retrieved from http://ijds.lemoyne.edu/journal/2_1/index.html

Bertau, M. C., \& Gonçalves, M. (2007). Looking at "Meaning as movement" in development: Introductory reflections on the developmental origins of the dialogical self. International Journal for Dialogical Science, 2, 1-12. Retrieved from http:// ijds.lemoyne.edu/journal/2_1/index.html

Cortini, M., Mininni, G., \& Manuti, A. (2004). The diatextual construction of the self in short message systems. Identity, $4,355-370$.

Creswell, J. W. (2010). Projeto de Pesquisa: Métodos Qualitativo, Quantitativo e Misto. Porto Alegre: Artmed.

Cunha, C. (2007). Constructing organization through multiplicity: a microgenetic analysis of self-organization in the dialogical self. International Journal for Dialogical Science, 2, 287-316. Retrieved from http://ijds.lemoyne.edu/journal/2_1/index.html

Damásio, A. R. (2000). O mistério da consciência. (L. T. Motta, Trad.). São Paulo:

Companhia das Letras. (Originalmente publicado em 1999)

DeSouza, M. L., \& Gomes, W. B. (2009). Temporalidade e espacialidade na estrutura do self nas abordagens semiótica e dialógica. Psicologia em Estudo, 14, 365-373.

DeSouza, M. L., DaSilveira, A., \& Gomes, W. B. (2008). Verbalized inner speech and the expressiveness of self-consciousness. Qualitative Research in Psychology, 5(2), 154-170.

Duarte, F., \& Gonçalves, M. M. (2007). Negotiating motherhood: a dialogical approach. International Journal for Dialogical Science, 2, 249-275. Retrieved from http://ijds.lemoyne.edu/ journal/2_1/index.html

Fogel, A., Koeyer, I., Bellagamba, F. \& Bell, H. (2002). The dialogical self in the first two years of life. Theory \& Psychology, 12, 191-205.

Florenskaya, T. A. (1989). Psychological problems of dialogue in light of the ideas of M. M. Bakhtin and A. A. Ukhtomskii. Soviet Psychology, 27, 29-40.

Gil, A. C. (2002). Como elaborar projetos de pesquisa. São Paulo: Atlas.

Gomes, W. B. (Ed.) (1998). Fenomenologia e pesquisa em psicologia. Rio Grande do Sul: Ed. Universidade/UFRGS.

Gonçalves, M. M., \& Salgado, J. (2001). Mapping the Multiplicity of the Self. Culture \& Psychology, 7, 367-377.

Harré, R., \& Gillett, G. (1999). A mente discursiva: os avanços na ciência cognitiva. (D. Batista, Trad.). Porto Alegre: Artmed.

Hermans, H. J. M. (2000). Valuation, innovation and critical personalism. Theory \& Psychology, 10, 801-814.

Hermans, H. J. M. (2001). The construction of a personal position repertoire: method and practice. Culture \& Psychology, 7, 323-365.

Hermans, H. J. M., Kempen, H. J. G., \& Van Loon, R. J. P. (1992). The Dialogical Self: beyond individualism and rationalism. American Psychologist, 47, 23-33. 
Hermans, H. J. M., \& Kempen, H. J. G. (1993). The Dialogical Self: Meaning as Movement. San Diego: Academic Press.

Husserl, E. (1986). A idéia da fenomenologia (A. Morão, Trad.). Lisboa: Edições 70.

Lanigan, R. (1992). The human science of communicology. Pittsburgh: Duquesne University Press.

Leiman, M. (2002). Toward semiotic dialogism: The role of sign mediation in the dialogical self. Theory \& Psychology, 12, 221-235.

Lewis, M. D. (2002). The dialogical brain: Contributions of emotional neurobiology to understanding the dialogical self. Theory \& Psychology, 12, 175-190.

Lyra, M. (2005). O modelo EEA para a investigação da emergência e desenvolvimento da comunicação e do self: bases conceituais e fundamentos teórico-metodológicos. Estudos de Psicologia, $11,25-33$.

Lysaker, J. T. (2006). "I am not what I seem to be". International Journal for Dialogical Science, 1, 43-45. Retrieved from http:// ijds.lemoyne.edu/journal/1_1/index.html

Mancuso, J. C., \& Sarbin, T. R. (1983). The self-narrative in the enactment of roles. In T. R. Sarbin, \& K. Scheibe (Eds.), Studies in social identity (pp. 254-273). New York: Praeger.

Michotte, A. (1963). The perception of causality (T. R. Miles \& E. Miles, Trads.). London: Methuen. (Originalmente publicado em 1946)

Morin, A. (1993). Self-talk and self-awareness: on the nature of the relation. The Journal of Mind and Behavior, 14, 223-234.

Morin, A. (2001). The split brain debate revisited: on the importance of language and self recognition for right hemispheric consciousness. Journal of Mind and Behavior 22, 107-118.

Morin, A. (2002). Right hemispheric self-awareness: A critical assessment. Consciousness and Cognition, 11, 396-401.

Morin, A. (2003). Inner speech and conscious experience: Talking to ourselves is important in developing a sense of self. Science \& Consciousness Review, 4, 1-6.

Raggatt, P. T. F. (2000). Mapping the dialogical self: towards a rationale and method of assessment. European Journal of Personality, 14, 65-90.

Raggatt, P. T. F. (2010). The self positioned in time and space: dialogical paradigms. Theory \& Psychology, 20(3), 451-460.

Rosenberg, M., \& Turner, R. H. (Eds.). (1981). Social Psychology: Sociological Perspectives. New York: Basic Books.
Salgado, J. (2008, agosto). Analysis of the "El Guerrillero". Trabalho apresentado na Fifth International Conference on the Dialogical Self, Cambridge, Reino Unido.

Santos, M. A. (2007). Movimentos dialógicos do self em psicoterapia. (Dissertação de mestrado não publicada). Universidade Federal do Rio Grande do Sul, Porto Alegre.

Santos, M. A., \& Gomes, W. B. (2010). Self dialógico: teoria e pesquisa. Psicologia em Estudo, 15, 353-361.

Sarbin, Th. R. (1986). The narrative as a root metaphor for psychology. In Th. R. Sarbin (Ed.), Narrative psychology: The storied nature of human conduct (pp. 3-21). New York: Praeguer.

Sarbin, Th. R. (1989). Emotions as narrative emplotments. In M. J. Packer \& R. B. Addison (Eds.), Entering the circle: Hermeneutic investigation in psychology (pp. 185-201). Albany, NY: SUNY Press.

Sarbin, Th. R. (1990). The narrative quality of action. Theoretical and Philosophical Psychology, 10, 49-65.

Taylor, C. (1997). As fontes do self: a construção da identidade moderna. (A. U. Sobral e D. A. Azevedo, Trads.). São Paulo: Edições Loyola. (Originalmente publicado em 1989)

Valsiner, J. (2002). Forms of dialogical relations and semiotic autoregulation within the self. Theory \& Psychology, 12, 251-265.

Vasil'eva, I. I. (1988). The importance of M. M. Bakhtin's idea of dialogue and dialogic relations for the psychology of communication. Soviet Psychology, 26, 17-31.

Wiley, N. (1996). O self semiótico. (L. P. Rouanet, Trad.). São Paulo: Edições Loyola. (Originalmente publicado em 1994)

Wiley, N. (1994). The semiotic self. Chicago: The Univ. Chicago Press.

Wiley, N. (2006). Pragmatism and the dialogical self. International Journal for Dialogical Science [On-line Journal], 1, 43-45. Retrieved from http://ijds.lemoyne.edu/journal/1_1/index.html

Recebido em 14.09.2009

Primeira decisão editorial em 15.06.2010

Versão final em 18.08.2011

Aceito em 31.08.2012 